\title{
Comparing the effects of general and spinal anaesthesia on the postoperative pain intensity in patients undergoing emergent or elective caesarean section
}

\author{
Reyhan Arslantaş ${ }^{1}$, Tumay Oncel Umuroglu². \\ 1 Health Sciences University Kartal Dr.Lutfi Kırdar Training and Research Hospital, Anesthesiology and \\ Reanimation Clinic - Istanbul (Turkey), \\ 2 Marmara University, School of Medicine, Department of Anesthesiology and Reanimation - Istanbul \\ (Turkey)
}

\section{Background and Goal of Study:}

Pain experienced in the post-caesarean section period is closely related to the preoperative anxiety, urgency of the procedure and anaesthesia method used $(1,2)$. The effects of the preoperative anxiety and anaesthesia methods (general versus regional anaesthesia) on the post-caesarean pain intensity have been previously investigated, but studies comparing the effects of regional and general anaesthesia in elective and emergent caesarean sections (CS) are lacking (3). The main objective of this study is to compare the effects of general and spinal anaesthesia on postoperative pain intensity and analgesic agent requirements in patients scheduled for emergent or elective CS. The secondary aim is to determine the satisfaction of the patients, in the postoperative period.

\section{Materials and Methods:}

A prospective, observational study of patients undergoing emergent or elective caesarean delivery under spinal or general anaesthesia. Postoperative pain intensity and analgesic requirements, postoperative complications and patients' satisfactions were evaluated for up to $48 \mathrm{~h}$ after surgery.
Results and Discussion:

This is a total of 212 parturients were enrolled; 104 (51 electives, 54 emergents) patients received general and 108 (53 electives, 51 emergents) patients received spinal anaesthesia. Patients in the emergent CS groups under spinal and general anaesthesia had higher 11-point Numeric Rating Scale (NRS) scores during the first $24 \mathrm{~h}$ after surgery, when compared to patients with elective CS groups. In addition, NRS pain scores were significantly increased in the emergent CS group, when compared to the elective CS under regional anaesthesia during the first postoperative $24 \mathrm{~h}$. Postoperative analgesic requirements were not significantly different between patients underwent for emergent or elective CS.

Conclusion(s):

The effects of general and spinal anaesthesia on postoperative pain were not comparable in emergent and elective CS performed under general or spinal anaesthesia. Therefore, the influence of these methods on postoperative pain intensity should not be a determining factor in choosing the anaesthesia method in emergent and elective CS.

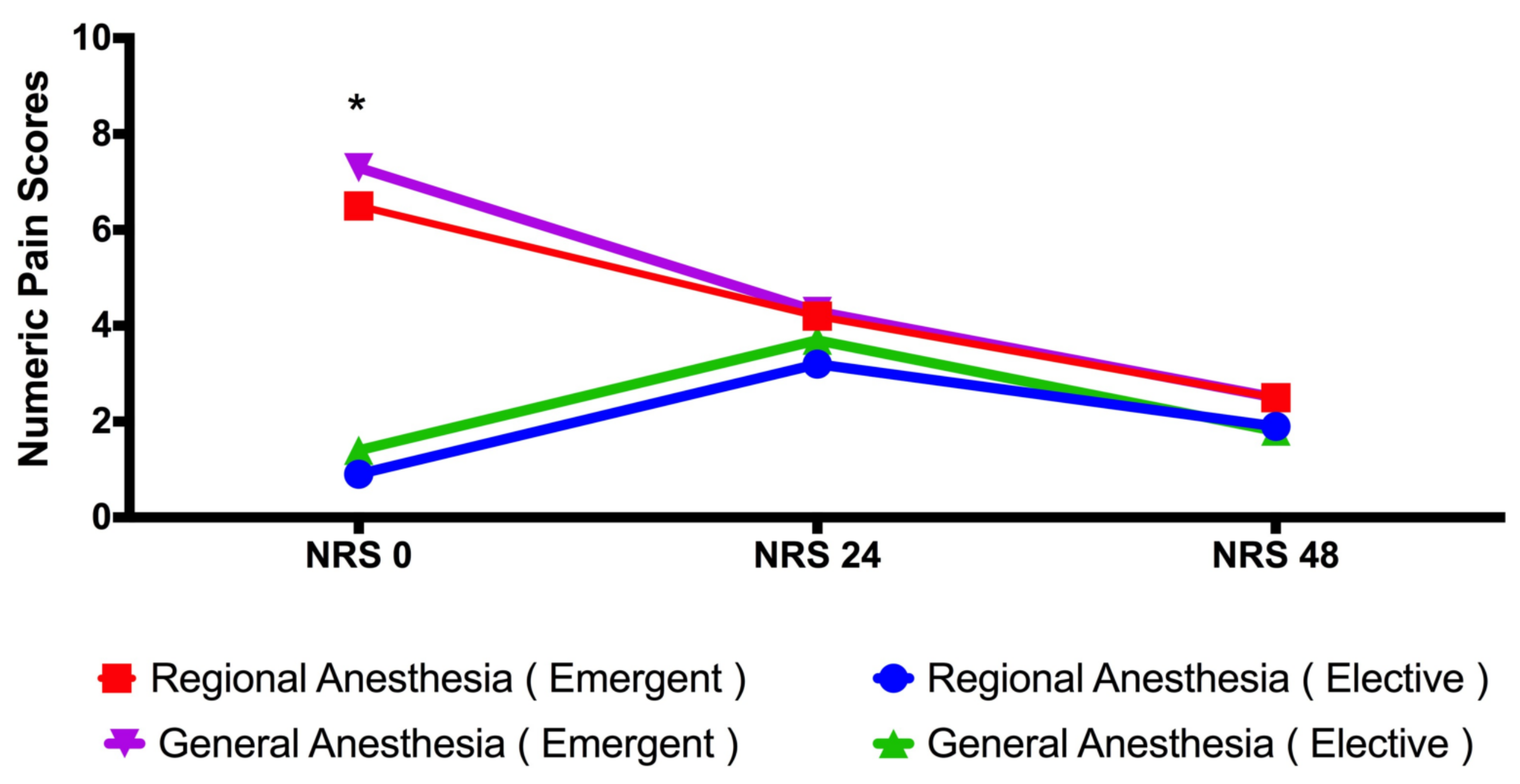

References:

1. Gorkem, U.,Minerva Anestesiol,2016.82(9):p.974-80.

2. Kessous, R.,Arch Gynecol Obstet,2012.286(1):p.75-9. 